\title{
PERCEPÇÕES DE ESTUDANTES DE UM CURSO DE FORMAÇÃO DOCENTE ACERCA DO MEIO AMBIENTE
}

\section{STUDENTS' PERCEPTION REGARDING ENVIRONMENT IN A TEACHER TRAINING COURSE}

\author{
Jéssica Engel do Nascimento ${ }^{1}$ \\ Eduarda Maria Schneider ${ }^{2}$ \\ Lourdes Aparecida Della Justina ${ }^{3}$
}

\begin{abstract}
Resumo: Neste estudo investigamos as percepções de Meio Ambiente de estudantes de um curso de Formação de Docentes para Educação Infantil e Anos Iniciais do Ensino Fundamental, Nível Médio, de um município do oeste do Paraná/Brasil. A construção dos dados ocorreu mediante questionário, no qual deveriam desenhar seu entendimento de Meio Ambiente, e posteriormente foi realizada uma entrevista individual, permitindo a justificativa sobre o desenho inicialmente elaborado. As informações reunidas foram submetidas à análise de conteúdo e a análise semiótica. Verificamos percepções de Meio Ambiente como biosfera, natureza, recurso, lugar em que se vive e como problema. Essas percepções foram elaboradas a partir dos contextos históricos, sociais e culturais individuais em que cada um está imerso. Entretanto, considerando o envolvimento e a relevância desses futuros profissionais no processo educacional, recomenda-se uma constante formação crítica para possibilitar discursos amplos e fundamentados no respeito, no conhecimento e na democracia sobre as relações ambientais.
\end{abstract}

Palavras-chave: Formação inicial de professores; Educação ambiental; Percepção ambiental.

\begin{abstract}
In this study, we investigated the Environmental perception of students in a Teacher Training Course for Early Childhood Education and Initial Years of Elementary Education, Middle Level of a municipality in the western part of Paraná/Brazil. The construction of the data was done through a questionnaire, in which they should draw their understanding of the Environment, and later an interview was carried out with each student separately, allowing them to talk about the drawing initially made. The collected information was submitted to content and semiotic analyses. It was possible to evidence environmental perceptions as biosphere, nature, resource, from where one lives, and as a problem. These perceptions have been drawn from the individual historical, social, and cultural contexts in which each student is immersed. However, considering the involvement and relevance of these future professionals in the educational process, a constant critical formation is essential to enable broad and reasoned discourses based on respect, knowledge, and democracy about relationships Environment.
\end{abstract}

Keywords: Initial teacher education; Environmental education; Environmental perception.

\footnotetext{
${ }^{1}$ Doutoranda em Educação em Ciencias e Educação Matemática, Universidade Estadual do Oeste do Paraná (Unioeste). Universidade Estadual do Oeste do Paraná (Unioeste), Cascavel, Paraná, Brasil. E-mail: jessicaenge193@hotmail.com

${ }^{2}$ Doutora em Educação para a Ciência e o Ensino de Matemática, Universidade Estadual de Maringá (UEM). Docente da Universidade Tecnológica Federal do Paraná (UTFPR). Santa Helena, Paraná, Brasil. E-mail: eduardamaria.schneider@gmail.com

${ }^{3}$ Doutora em Educação para Ciência, Universidade Estadual Paulista Julio de Mesquita Filho (Unesp/Bauru). Docente da Universidade Estadual do Oeste do Paraná (Unioeste). Grupo de Pesquisa em Educação em Ciências e Biologia - GECIBIO. Cascavel, Paraná, Brasil. E-mail: lourdesjustina@gmail.com
} 


\section{Introdução}

Os debates sobre a educação ambiental (EA) no mundo contemporâneo estão relacionados às problemáticas ambientais, fruto das escolhas e ações humanas, por vezes preocupantes para os mais variados setores da sociedade. Com ênfase a partir da Revolução Industrial, a relação humana de intervenção e transformação da natureza ocorre desenfreadamente, sem ou com pouca reflexão sobre seus efeitos (TOZONI-REIS, 2004).

A partir da década de 1960, as preocupações com a perda da qualidade ambiental tomam formas no cenário mundial, sendo realizada em 1968, em Roma, uma reunião de cientistas dos países industrializados, o Clube de Roma, com o objetivo de discussão sobre o consumo e as reservas de recursos naturais não renováveis e o aumento da população mundial até o século XXI. Como resultado, compreenderam a urgência para mudança de postura frente ao consumo dos recursos naturais, sendo preciso buscar meios para sua conservação e controle do crescimento populacional (DIAS, 2004; REIGOTA, 2009).

Não obstante, os debates do Clube de Roma propiciaram o entendimento do problema ambiental em nível planetário; com isso, em 1972, em Estocolmo, na Suécia, a Organização das Nações Unidas (ONU) realizou a Primeira Conferência Mundial de Meio Ambiente Humano, em que a discussão se voltava para a poluição proveniente das indústrias e no intuito de "[...] estabelecer uma visão global e princípios comuns que servissem de inspiração e orientação à humanidade, para preservação e melhoria do ambiente humano" (DIAS, 2004, p.79). Uma resolução importante proveniente dessa conferência foi a necessidade de educar os cidadãos para encontrar meios ou caminhos para a solução dos problemas ambientais. Como apontou Tozoni-Reis (2004, p. 4), é necessária "[...] a educação dos indivíduos para o uso mais equilibrado dos recursos". Desde então, a educação passa a ser vista como um instrumento capaz de contribuir para as possíveis soluções da crise ambiental (DIAS, 2004; DIAS, 2012).

Após os eventos mencionados, houve outros que contribuíram para a abordagem e visibilidade das questões ambientais, como o Seminário Internacional sobre Educação Ambiental, realizado em Belgrado (antiga Iugoslávia), em 1975, e a Conferência Intergovernamental, realizada em Tbilissi (Geórgia - URSS), em 1977. Esses eventos, entre outros realizados, buscaram discutir as relações com o Meio Ambiente (MA), atribuindo importância à educação ambiental dos sujeitos, e utilizando esta como caminho 


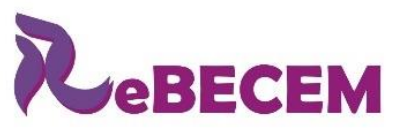

Revista Brasileira de Educação em

Ciências e Educação Matemática

DOI: https://doi.org/10.33238/ReBECEM.2020.v.4.n.2.24230

para a sensibilização e conhecimento científico da temática. Resumidamente, podemos dizer que a educação assume um papel único, sendo necessária para construção de uma sociedade justa e ecologicamente equilibrada, condição compreendida como indispensável para manutenção da vida no planeta e para a sobrevivência das espécies.

Segundo Ramos (2001, p. 206), a educação ambiental “[...] deve ser capaz de transformar as relações do homem com o ambiente, entre o indivíduo e a natureza", visto que, segundo o autor, o indivíduo degrada e destrói o ambiente, agindo de maneira ignorante. Assim, a educação ambiental surge como possibilidade para educar ambientalmente a sociedade. Entretanto, durante a formação do sujeito, ocorrem inúmeras influências históricas, sociais, éticas, entre tantas outras que irão modificá-lo e reconstruí-lo. Por isso, possivelmente, a educação ambiental sozinha não seja suficiente para uma formação ambiental responsável, mas a combinação desta com a construção e desenvolvimento histórico, político, econômico, social e ético em que o sujeito possui contato provavelmente possa sensibilizar e alterar suas escolhas e ações.

Considerando a relevância da educação na formação dos sujeitos, concordamos com Mariani Júnior (2008) ao ressaltar que o aprendizado e o conhecimento sobre as questões ambientais possibilitam a ampliação da compreensão e da visão sobre o mundo nas relações estabelecidas entre os seres, bem como nas individualidades da vida do ser humano e sua capacidade de intervenção nas demais formas de vida e no Meio Ambiente. Desse modo, acredita-se que seja possível o despertar de uma consciência social e ambiental sobre as causas dos problemas locais e globais, possibilitando, por meio da educação, um caminho de reflexão e de mudança. Visto que, na contemporaneidade, diversas são as problemáticas ambientais, como o consumo excessivo e a produção de lixo, desmatamento, queimadas, poluição, uso indiscriminado de agrotóxicos, entre outros que resultam em grandes catástrofes.

Acreditando na potencialidade da educação para a conscientização e qualificação da sociedade, Oliveira, Amorim e Pizzi (2018, p.265) evidenciam que a formação docente deve promover a preparação e instrumentalização de profissionais com possibilidade e competência de oferecer condições para a interação destes com as inúmeras transformações sociais, políticas e educacionais presentes no ambiente escolar. Ainda, que esses estejam atualizados e em constante reflexão crítica sobre a própria experiência docente, para refazê-la, transformá-la e melhorá-la.

Considerando o apresentado, entendemos que a educação se constitui como um dos caminhos para posicionamentos críticos em relação às temáticas ambientais, e os 


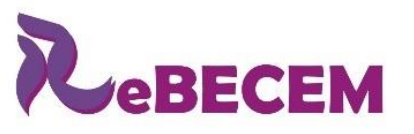

Revista Brasileira de Educação em

Ciências e Educação Matemática

DOI: https://doi.org/10.33238/ReBECEM.2020.v.4.n.2.24230

professores, como agentes diretos da educação, são responsáveis na decisão de como trabalhar a temática ambiental para possibilitar a compreensão da complexidade da relação do MA para seus alunos. Posto isso, indagamos: quais são as percepções de Meio Ambiente que os futuros professores possuem, uma vez que eles atuarão na formação de cidadãos na sociedade?

A presente pesquisa, apoia-se no entendimento que a clareza da percepção dos professores, e no caso dos futuros professores, sobre o Meio Ambiente possibilita diagnosticar limitações de conhecimentos teóricos e práticos sobre a temática ambiental nos seus cursos de formação, os quais podem ser revistos e trabalhados posteriormente, em busca de incentivar a adoção de hábitos e atitudes responsivos em relação ao meio ambiente e, contribuir positivamente no processo de ensino e aprendizagem sobre a EA.

Ademais, a pesquisa se faz pertinente, pois assim como apontado por Reigota (1998), a prática pedagógica e a compreensão que o educador possui de Meio Ambiente podem influenciar a aprendizagem dos estudantes quanto a conteúdos e conceitos referentes à EA.

Para tanto, entendemos que o termo Meio Ambiente (MA) possui inúmeras compreensões, as quais são provenientes dos contextos históricos e sociais distintos e não excludentes, pois diferentes percepções podem estar presentes em um mesmo grupo social em determinado período. Nessa perspectiva, é pertinente compreender como ocorre a elaboração das percepções e investigar algumas das definições de MA presentes na literatura.

$\mathrm{Na}$ continuidade, trazemos alguns referenciais teóricos que contribuem no entendimento sobre como ocorre a elaboração das percepções, e algumas compreensões de MA descritas na literatura. Esse arcabouço teórico norteou a análise das percepções de MA dos participantes da investigação, realizada na sequência.

\section{Elaboração das percepções}

$\mathrm{O}$ ato de perceber um objeto, um fenômeno ou um acontecimento ocorre de forma distinta entre os sujeitos, pois cada indivíduo possui uma construção histórica e social que influencia diferentemente na percepção. De acordo com Cunha (2009, p. 27), “o fato de um objeto ser percebido de muitas formas ou de nenhuma forma deve-se ao modo individualizado pelo qual recebemos e transformamos a percepção”. Assim, a psicologia 


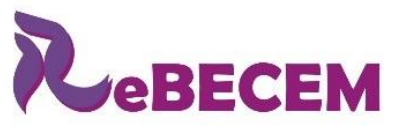

Revista Brasileira de Educação em

Ciências e Educação Matemática

DOI: https://doi.org/10.33238/ReBECEM.2020.v.4.n.2.24230

aponta que "[...] é preciso considerar a pessoa que percebe e o ato da percepção, porque ambos determinam o fenômeno" (CUNHA, 2009, p. 27).

Segundo Luria (1990, p. 37), as evidências acumuladas provenientes do conjunto de experimentos desenvolvidos nos estudos de percepção, como interpretação de cores e formas por indivíduos de distintas construções sociais, sugerem “[...] que a percepção é um processo complexo envolvendo complexas atividades de orientação, uma estrutura probabilística, uma análise e síntese dos aspectos percebidos e um processo de tomada de decisão".

Nessa perspectiva, os estudos de Luria (1990, 2001), Vigotski (1998) e de Cunha (2009) apontam que linguagem e percepção estão relacionadas, sendo importantes para o desenvolvimento cognitivo, uma vez que a compreensão do todo envolve a aquisição de sentido e significado possível pela ligação da linguagem com a percepção. Com o exposto, temos que a percepção é uma atividade cognitiva complexa, pois utiliza diversos dispositivos auxiliares, bem como emprega uma íntima participação da linguagem (LURIA, 1990).

Entretanto, a percepção de imagens ou de objetos reais possui sentido apenas quando a imagem visualizada, mediante a linguagem, interage com o intelecto, gerando significado. Já os signos compreendem os símbolos, que são importantes para a percepção, pois contribuem ou auxiliam na relação entre indivíduo e objeto, desencadeando compreensões históricas e culturais sobre o objeto ou sobre a situação. Assim, a linguagem e os signos possuem papel especial na organização e no desenvolvimento dos processos de pensamento (LURIA, 2001).

Nesse sentido, entendemos que a percepção é formada pelo conjunto do campo sensorial, conjunto esse que envolve os sentidos, a fala, os signos e os instrumentos em interação com o campo cognitivo/mental, considerando a construção histórica e social do indivíduo. Vale dizer que a formulação/construção da percepção está relacionada com vários fatores inerentes a cada sujeito.

Conforme apresentado, entendemos que a forma do ser humano perceber o meio envolve diferentes elementos, os quais influenciam no estabelecimento das relações em sociedade. Possuindo essa compreensão, nota-se a pertinência de pesquisas que evidenciem a percepção ambiental dos sujeitos, uma vez que esta é construída com base nas relações estabelecidas deles com o meio, sendo possível discutir as possibilidades de entendimento sobre os posicionamentos decorrentes da interação dos indivíduos com o 


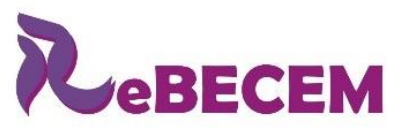

\section{Revista Brasileira de Educação em \\ Ciências e Educação Matemática}

DOI: https://doi.org/10.33238/ReBECEM.2020.v.4.n.2.24230

mundo e sua postura em educação ambiental. Na continuidade abordamos algumas compreensões de MA já mapeadas, presentes na literatura.

\subsection{Compreensões de Meio Ambiente}

Dentre os autores que definem MA, os registros históricos remetem a Espinosa, pensador que nasceu em Amsterdã, em 1632, mudando-se posteriormente para a Holanda, local em que viveu até sua morte, em 1677. Na contemporaneidade, é considerado um referencial da reflexão e da ação ambiental devido seus escritos e ideias estarem à frente do seu tempo. Espinosa não escreveu sobre Ecologia, mas fez fortes críticas àquele conhecimento que nascia, principalmente à forma dominadora de se tratar a natureza, subordinando-a à vontade do ser humano (SAWAIA, 2006).

De acordo com Sawaia (2006), em 'Espinosa: o precursor da ética e da educação ambiental com base nas paixões humanas', o pensador possuía uma visão unificadora de MA que integra o ser humano ao cosmos, conforme exposto:

[...] cada realidade individual é uma manifestação deste Todo, que se
individualiza e se concretiza em unidades autônomas, como os homens, os
animais e o meio ambiente. Daí se deduz que todos os seres estão intimamente
interligados, embora cada um mantenha sua dignidade de realidade singular na
plenitude de sua especificidade. Isto significa que não é correto falar em
supremacia do homem sobre o meio ambiente. Ambos constituem uma
unidade, de forma que a saúde de um depende da do outro (SAWAIA, 2006,
p. 82).

Espinosa argumenta que o ser humano faz parte do MA, transformando-o e transformando-se por ele, constituindo-se, assim, um ser integrante e indissociável. Logo, se o MA é afetado, o ser humano também sofre as consequências desse ato. Tal crítica defendida por Espinosa faz-se presente na sociedade atual, uma vez que alguns cidadãos acreditam que os recursos naturais são para servir o homem, os quais são explorados sem consciência das consequências atuais e futuras da conduta humana.

Nota-se que a busca por definição para MA é antiga e inerente a cada período histórico, social, político e cultural que o sujeito participa. Ou seja, inúmeros fatores irão influenciar na percepção de MA que cada indivíduo possui.

Recorrendo à legislação brasileira, está presente na lei federal nº 6.938, de 1981, que institui a Política Nacional do Meio Ambiente - PNMA, em seu Artigo $3^{\circ}$, a seguinte definição legal de MA: “[...] o conjunto de condições, leis, influências e interações de ordem física, química e biológica, que permite, abriga e rege a vida em todas as suas formas" (BRASIL, 1981). Assim, entende-se MA como um conjunto amplo e holístico 


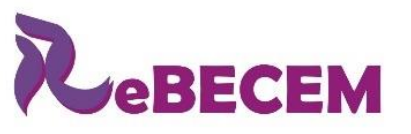

\section{Revista Brasileira de Educação em \\ Ciências e Educação Matemática}

DOI: https://doi.org/10.33238/ReBECEM.2020.v.4.n.2.24230

de interações, não delimitando apenas um local ou ambiente, mas contemplando a reunião dos fatores bióticos e abióticos.

Reigota, em 1988, apresentou uma representação de Meio Ambiente, na qual este não ficava restrito ao meio natural. Dessa forma, definiu-o como:

\section{[...] um lugar determinado e /ou percebido onde estão em relação dinâmica e em constante interação os aspectos naturais e sociais. Essas relações acarretam processos de criação cultural e tecnológica e processos históricos e políticos de transformações da natureza e da sociedade (REIGOTA, 2009, p.36).}

Nessa visão, a compreensão de MA pode ser considerada como socioambiental, pois leva em conta não apenas os aspectos naturais e físicos, mas também as relações culturais, históricas, sociais e tecnológicas entre os elementos envolvidos (SILVA, 2009).

Reigota (1998) classificou as representações sociais mais comuns de MA em três categorias: naturalista, antropocêntrica e globalizante. Na categoria naturalista se encaixam as representações que associam a ideia de MA à de ecossistema, voltado apenas à natureza, evidenciando seus aspectos naturais como fauna, flora e aspectos físicoquímicos, mas exclui o ser humano desse contexto; o ser humano é considerado um observador externo. Já na visão antropocêntrica, o meio ambiente é percebido pelos seus recursos naturais, os quais são fontes a serem utilizadas e gerenciadas pelo ser humano, úteis para as necessidades e sobrevivência humana. Finalmente, a visão globalizante concebe o ser humano ou a sociedade em relação com o meio ambiente, englobando aspectos políticos, sociais, culturais, econômicos e filosóficos. Nesta última visão, o ser humano não exerce poder dominante sobre a natureza, mas, sim, é compreendido como ser social que vive em comunidade (REIGOTA, 1998; OENNING; CARNIATTO, 2011).

Essas três denominações de ambiente são notórias na atualidade, e outros autores, como Sauvé (2005), já apresentaram outras mais, ampliando o leque de possibilidades de compreensões sobre o MA. Assim, buscando em outros autores, Silva (2000, p.20) apresenta MA como: “[...] a interação do conjunto de elementos naturais, artificiais e culturais que propiciem o desenvolvimento da vida em todas as suas formas. A integração busca assumir uma concepção unitária do ambiente, compreensiva dos recursos naturais e culturais".

Considerando os apontamentos já realizados, o MA abrange o meio físico, químico e biológico, integrando dessa forma a natureza original e artificial, bem como o solo, o ar, a água, a flora, o patrimônio histórico, cultural, social, político, entre outros.

Autores como Silva (2002, p.51) compreendem MA como um todo, conforme segue: "Em suma: ambiente é tudo, material e imaterial, que cerca e engloba o homem. 
DOI: https://doi.org/10.33238/ReBECEM.2020.v.4.n.2.24230

E, sem dúvida, a qualidade de vida sob o aspecto tanto físico quanto emocional depende da interação salutar de todos esses elementos”. Todavia, Brügger (2004, p.62) adverte que essa é uma visão muito simplista e generalista, exprimindo pouco conteúdo:

Quando se absolutiza alguma coisa, freqüentemente se esvazia o seu conteúdo.
O adjetivo "ambiental" deve ser antes de qualquer coisa, uma outra forma de
ver o mundo. As sociedades industriais nas quais vivemos são extremamente
"não-ambientais" e por isso mesmo encontramos sérias dificuldades em pensar
em uma sociedade ou cultura "ambiental".

Para Sauvé (2005), o MA pode ser entendido de outros modos, como: natureza (para apreciar, para respeitar, para preservar), recurso (para gerir, para repartir), problema (para prevenir, para resolver), sistema (para compreender, para decidir melhor), lugar em que se vive (para conhecer, para aprimorar), biosfera (onde viver junto e em longo prazo), projeto comunitário (em que se empenhar ativamente), território entre os povos indígenas (em que a relação de identidade com o meio é estritamente importante) e paisagem (possibilita caminho para interpretação dos contextos locais, com destaque a dinâmica de sua história e seus símbolos). Para explicar essas possibilidades de apreensões sobre MA, a autora defende que a definição ou entendimento de MA está atrelado a contextos culturais determinados, argumentando ser "[...] mediante um conjunto de dimensões entrelaçadas e complementares que a relação com o meio ambiente se desenvolve" (SAUVÉ, 2005, p.319).

De acordo com Santos e Maroti (2013), MA constitui-se de um conjunto de elementos bióticos e abióticos, que se relacionam e se influenciam, formando um equilíbrio dinâmico. Conclui, ainda, que o homem não se enxerga como parte desse equilíbrio, entretanto ele também é MA, e não um conjunto a parte ou um denominador deste. Entretanto, é unânime a certeza que o ser humano precisa da natureza.

Logo, com os apontamentos e algumas definições de MA abordadas nesta seção, nota-se que com o decorrer dos anos, das influências sofridas e das singularidades de cada indivíduo, as compreensões de MA mudam, são complementadas, reformuladas, ressignificadas. Ou seja, este breve texto não comporta as infinidades de entendimentos sobre MA, e não cabe aqui o fazer, mas, sim, demonstrar que MA pode e é compreendido de distintas maneiras, de acordo com as particularidades de cada sujeito nas suas construções e nuances sociais, históricas, ambientais, éticas, entre outras. Entretanto, na presente investigação, compartilharemos dos entendimentos de MA apresentados pela pesquisadora Sauvé (2005). Na sequência, traçamos o percurso metodológico que conduziu o trabalho. 


\section{Percurso Metodológico}

A presente investigação teve como pressuposto metodológico uma pesquisa de caráter qualitativo, pois ela contempla uma infinidade de significados, crenças, motivos, valores e atitudes que exigem aprofundamento na análise e interpretação das relações, dos processos e dos fenômenos que não se restringem à operacionalização das variáveis (MINAYO, 2010; MARCONI; LAKATOS, 2011). Entende-se, portanto, ser uma tentativa de compreender detalhadamente as situações pertinentes ao objeto de investigação, assim como afirma Flick (2009, p. 20) ao apontar a pesquisa qualitativa como sendo "[...] de particular relevância ao estudo das relações sociais devido à pluralização das esferas da vida".

Os sujeitos da pesquisa foram 15 estudantes do quarto ano do Curso de Formação de Docentes para Educação Infantil e Anos Iniciais do Ensino Fundamental, em Nível Médio, na modalidade Normal, do ano de 2017, de um município do oeste do estado do Paraná/Brasil, os quais foram codificados de A1 a A15.

Buscando compreender como esses estudantes percebem o MA, foram utilizados como instrumentos de constituição de dados um questionário e uma entrevista individual, em momentos distintos, os quais foram realizados na instituição escolar e no período em que os alunos estudavam. Inicialmente foi desenvolvido o questionário com os participantes, e após análise prévia desse instrumento, retornamos três dias depois ao colégio para a realização da entrevista individual. No questionário, foi proposto o desenvolvimento de um desenho sobre a percepção de MA para cada um dos estudantes. Já na entrevista, os estudantes explicaram a produção de seus desenhos. Posteriormente, foi realizada a transcrição e análise da entrevista de cada estudante.

Para reunir dados das produções artísticas realizadas, utilizamos a análise semiótica de imagens paradas proposta por Pen (2002). De acordo com a autora, os desenhos e as imagens devem ser dissecados e reduzidos a partes menores do todo, para então buscar o seu significado ou sentido de cada elemento, e, assim, mensurar o objetivo de quem o fez, ou seja, “[...] o processo de análise pode ser descrito como uma dissecação seguida pela articulação, ou a reconstrução da imagem semanticizada" (PEN, 2002, p. $325)$.

A entrevista com os alunos sobre os desenhos por eles produzidos fez-se necessária, pois os dados visuais neste trabalho (desenhos), não são autoexplicativos, eles possuem uma infinidade de significados para quem os produz (FLICK, 2009), devendo, 
DOI: https://doi.org/10.33238/ReBECEM.2020.v.4.n.2.24230

por isso, buscar a realização desse movimento dialético com seus ilustradores/idealizadores, a fim de haver mais coerência e justiça possível com as percepções dos sujeitos.

As informações textuais reunidas a partir da entrevista foram analisadas segundo a metodologia de análise de conteúdo proposta por Bardin (1977), por envolver um conjunto de técnicas que podem ser utilizadas "[...] para descrever e interpretar o conteúdo de toda classe de documentos e textos [...]", permitindo a reinterpretação e compreensão dos significados (MORAES, 1999, p.8).

Na primeira fase da análise de conteúdo procedemos a pré-análise, na qual realizamos a leitura flutuante das transcrições das entrevistas, juntamente com a análise semiótica do material dos desenhos produzidos. Este exercício possibilitou a organização do material reunido e a elaboração de indicadores para sua interpretação (categorias $a$ priori). No segundo momento, partimos para a exploração do material. Neste, os recortes destacados das entrevistas foram organizados em unidade de registros, as quais posteriormente foram agrupadas em categorias de acordo com sua correlação para possibilitar as inferências e as interpretações dos dados, pertencente a terceira e última fase da análise de conteúdo.

Neste sentido, os dados provenientes das produções dos desenhos juntamente com as entrevistas realizadas foram cruzados, buscando a confirmação do entendimento sobre MA dos sujeitos analisados, ou, ainda, a presença de posicionamentos complementares, que são expostos quando os sujeitos apresentam percepções em mais de uma categoria.

Posto isso, para a categorização dos dados referentes às percepções de MA, nos baseamos nas compreensões de Sauvé (2005), as quais são utilizadas como categorias $a$ priori, organizadas no Quadro 1 e que norteia a interepretação e discussão dos dados apresentados na sequência.

Quadro 1: Percepções de Meio Ambiente baseadas em Sauvé (2005)

\begin{tabular}{|c|c|}
\hline $\begin{array}{l}\text { Compreensão de Meio } \\
\text { Ambiente }\end{array}$ & Definição \\
\hline Natureza & Para apreciar, para respeitar, para preservar \\
\hline Recurso & Para gerir, para repartir \\
\hline Problema & Para prevenir, para resolver \\
\hline Sistema & Para compreender, para decidir melhor \\
\hline Lugar em que se vive & Para conhecer, para aprimorar \\
\hline Biosfera & Onde viver junto e em longo prazo \\
\hline Projeto comunitário & Em que se empenhar ativamente \\
\hline $\begin{array}{l}\text { Território entre os povos } \\
\text { indígenas }\end{array}$ & Em que a relação de identidade com o meio é estritamente importante \\
\hline Paisagem & $\begin{array}{l}\text { Possibilita caminho para interpretação dos contextos locais, com } \\
\text { destaque a dinâmica de sua história e seus símbolos }\end{array}$ \\
\hline
\end{tabular}

Fonte: Elaboração das autoras, 2018. 
DOI: https://doi.org/10.33238/ReBECEM.2020.v.4.n.2.24230

As compreensões de "paisagem", "território entre os povos indígenas", "projeto comunitário" e "sistema" não foram evidenciadas no material analisado. Nesse sentido na sequência apresentamos os resultados referentes as outras cinco compreensões elencadas no Quadro 1.

\section{Análise e Discussão dos Resultados}

As informações foram analisadas de acordo com a cartografia de Sauvé (2005), possibilitando a organização das percepções dos estudantes sobre MA em cinco subcategorias, sendo elas Percepção de Meio Ambiente como Biosfera, Natureza, Recurso, Lugar em que se vive, e Problema. Essas subcategorias estão organizadas e apresentadas em ordem decrescente na tabela 1 .

Tabela 1: Síntese das Percepções de Meio Ambiente

\begin{tabular}{cccc}
\hline Percepções de Meio Ambiente & Questionário & Entrevista & Total \\
Biosfera & A1, A4, A5, A6, A7, A15 & A1, A4, A5, A6, A7, A15 & 12 \\
Natureza & A8, A11, A12, A13, A14 & A8, A9, A11, A12, A13, A14 & 11 \\
Recurso & A2, A9, A10 & A2, A3, A10 & 6 \\
Lugar em que se vive & A3 & A3 & 2 \\
Problema & - & A3 & 1 \\
\hline
\end{tabular}

Fonte: Elaboração das autoras, 2018

$\mathrm{Na}$ análise dos desenhos dos estudantes, solicitados no questionário, ficou em evidência a subcategoria 'Biosfera'. Nesta foram evidenciadas percepções que abrangiam vários elementos, como o cotidiano da vida nas cidades e no campo, a natureza com seus recursos, a fauna e a flora, bem como os impactos ambientais. Esses foram os aspectos que, em conjunto, permitiram a classificação nessa subcategoria.

Essa compreensão de MA, de acordo com Sauvé (2005), abrange o viver junto e em longo prazo, considerando as inter-relações entre o local e o global e desenvolvendo uma consciência planetária, ampla de MA.

Nesse sentido, ao analisar os desenhos elaborados pelos estudantes, integraram essa subcategoria os alunos A1, A4, A5, A6, A7 e A15, totalizando seis aprendizes. O estudante A1 desenhou: 
Figura 1: A1

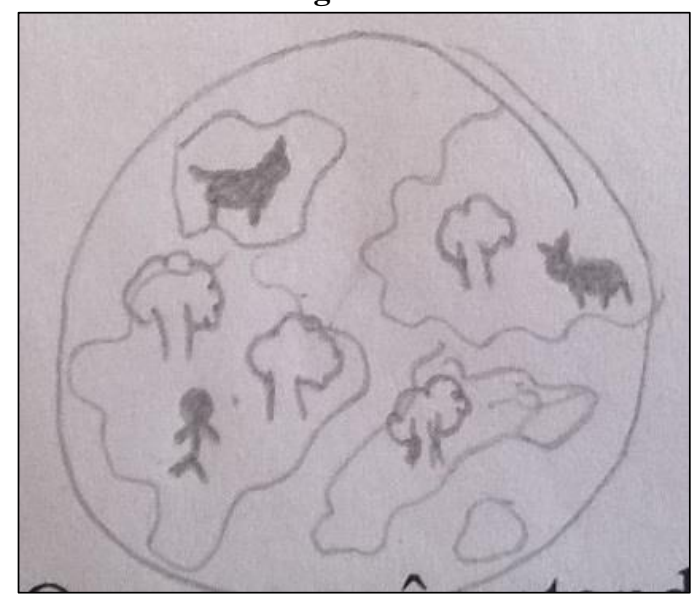

Fonte: Dados da pesquisa

No desenho de A1, ao realizar o processo de dissecação, notamos a referência ao planeta Terra, pois o estudante desenhou uma circunferência, cujo interior apresenta desenhos abstratos que provavelmente seriam os continentes, com a representação de animais quadrúpedes, um ser humano e árvores. Nesse sentido, entendemos que A1 possui uma Percepção de MA como Biosfera, envolvendo todo o planeta Terra.

Após a análise das entrevistas, percebemos que os seis alunos classificados inicialmente nessa subcategoria trouxeram subsídios que reiteraram a classificação inicial, confirmando a interpretação de seus desenhos sobre uma Percepção de MA como Biosfera, sendo eles A1, A4, A5, A6, A7 e A15. Na entrevista, A7 menciona:

\begin{abstract}
A7 - "Tá, eu quis demonstrar, assim, que tanto as árvores, rios, fazem tudo faz parte do meio ambiente, quanto nós seres humanos também, não é tipo árvores, e... as outras coisas também fazem parte da natureza, tipo está na natureza, não é só mata e rios, nós também fazemos parte da natureza".
\end{abstract}

Com o declarado, nota-se que, para A7, o MA é a união da natureza com seus elementos e o ser humano, com seus processos de industrialização. O ser humano também está incluído, ou seja, o MA não compreende apenas os animais, a flora e os recursos naturais. A representação da casa demonstra que A7 percebe que o ser humano realiza modificações em seu meio, podendo ser um indicativo sobre as modificações oriundas dos demais elementos da urbanização e industrialização. Portanto, de acordo com o mencionado por A7 na entrevista, entende-se que o MA seja o todo, abrangendo a natureza, com seus recursos, e a sociedade, com suas construções.

Essa percepção de MA de forma holística constitui-se como necessária para educadores, pois permite que eles compreendam a complexidade do MA, podendo exercer influência na transformação dos envolvidos no processo de ensino e na 
DOI: https://doi.org/10.33238/ReBECEM.2020.v.4.n.2.24230

aproximação destes às ações de melhoria das condições de vida no planeta (DINIZ; TOMAZELLO, 2005).

De acordo com Krzysczak (2016, p. 7), a percepção de MA como Biosfera “[...] foi provocada pela globalização do mercado, pela informação e também pela percepção sobre as inter-relações dos fenômenos ambientais locais e globais".

A segunda subcategoria que obteve expressividade significativa foi o Meio Ambiente como Natureza, com cinco alunos, A8, A11, A12, A13 e A14. Esta subcategoria faz referência aos locais com a natureza intocada pelo ser humano, que devem ser respeitados, admirados, apreciados pelos indivíduos (SAUVÉ, 2005); ele é percebido de maneira original, pura, sem a interferência ou presença do ser humano (KRZYSCZAK, 2016). Dentre os desenhos que permitiram inferir essa percepção, temos o de A8:

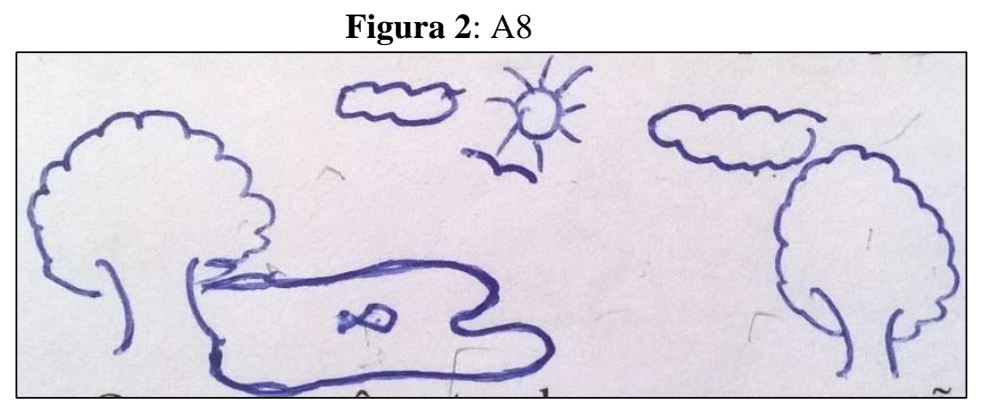

Fonte: Dados da pesquisa

Ao realizar o processo de dissecação, conforme proposto por Pen (2002), observamos a presença de árvores, rio, açude ou lago, peixe, pássaro, nuvens e sol. Os elementos expressos remetem à natureza, um local sem interferência humana, aparentemente "tranquila" e em "harmonia".

Na realização da entrevista, é percebida uma constância na quantidade de alunos com essa percepção, porém ocorre a inclusão do aluno A9, ficando constituída agora por A8, A9, A11, A12, A13 e A14. Ao interpelar A12 sobre a elaboração de seu desenho, obtivemos:

A12 - "É, assim, na hora que eu fui desenhar eu pensei assim, a primeira coisa que veio a cabeça foi a mata. Como eu moro quase no meio do mato, eu só desenhei as árvores e animais, como é a minha rotina".

Pesquisadora - "Você mora no sítio? No interior?"

A12 - “Sim. Aí eu esqueci de desenhar que nós também somos, né? Até mesmo as construções, o ser humano, tudo interligado. É aquele sistema, você vê meio ambiente-natureza. Então foi isso que eu fiz". 


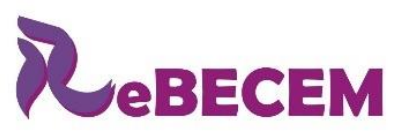

Revista Brasileira de Educação em

Ciências e Educação Matemática

DOI: https://doi.org/10.33238/ReBECEM.2020.v.4.n.2.24230

Verifica-se que A12 justifica o desenho realizado por pensar automaticamente na natureza ao ser indagado sobre MA, porém, ao menos em sua fala, demonstra reflexão ao incluir o ser humano e as construções ao MA. Entretanto, quanto ao desenho oriundo do questionário, a explicação do estudante retratou o MA como a Natureza.

Conforme percebido no desenho de A8 e na justificativa de A12, o ser humano, nessa subcategoria, não é incluído como parte do meio. Esse dado já está apontado em Reigota (2009, p. 16), ao mencionar que o ser humano "dificilmente se considera um elemento da natureza, mas um ser à parte, como um observador e/ou explorador dela". Sauvé (2005, p. 317) argumenta que é preciso eliminar a lacuna existente entre ser humano e natureza, reconstruindo o sentimento de pertença a esse fluxo de vida do qual participamos, tomando consciência " [...] de que, por meio da natureza, reencontramos parte de nossa própria identidade humana, de nossa identidade de ser vivo entre os demais seres vivos $[\ldots] "$, reestabelecendo os vínculos entre humanidade e natureza.

Percepções de MA como 'Natureza' também foram evidenciadas no trabalho de Garrido e Meirelles (2014) com alunos de $1^{\circ}$ e $5^{\circ}$ anos do Ensino Fundamental do município de Duque de Caxias, estado do Rio de Janeiro, e de Wollmann, Soares e Ilha (2015), no qual foram tabuladas 72,7\% indicações de percepções naturalistas e antropocêntricas sobre o MA em um grupo de professores no estado do Rio Grande do Sul/Brasil.

As percepções de Meio Ambiente como Recurso também estiveram presentes nos sujeitos investigados. Foram englobadas percepções que enfatizaram os recursos naturais provenientes da natureza, como madeira, frutos, água, peixes, entre outros, bem como destacaram sua necessidade para a sobrevivência humana. Essa subcategoria possui um viés antropocêntrico, no qual o ser humano está no centro do MA, denotando que a função do MA é servir aos seres humanos.

Recorrendo a Krzysczak (2016, p.6), o MA percebido como recurso “[...] é aquele que precisa ser gerenciado/administrado". Os recursos naturais, renováveis e não renováveis, são entendidos como herança coletiva, imprescindíveis para o sustento da qualidade de nossas vidas.

Nessa perspectiva, a partir do questionário, obtiveram-se três integrantes, A2, A9 e A10. No desenho de A2, ao realizar o processo de dissecação, percebemos a presença de uma flor, um coração em uma base ou pedestal, pássaros e rua. Com esse desenho e sua organização, A2 demonstra o MA ser um lugar idealizado, tranquilo e bonito. Além 
DOI: https://doi.org/10.33238/ReBECEM.2020.v.4.n.2.24230

do desenho elaborado, o aluno incluiu a frase, A2 - "O meio ambiente é o que nos sustenta, devemos amá-lo e protegê-lo”.

Figura 3: A2

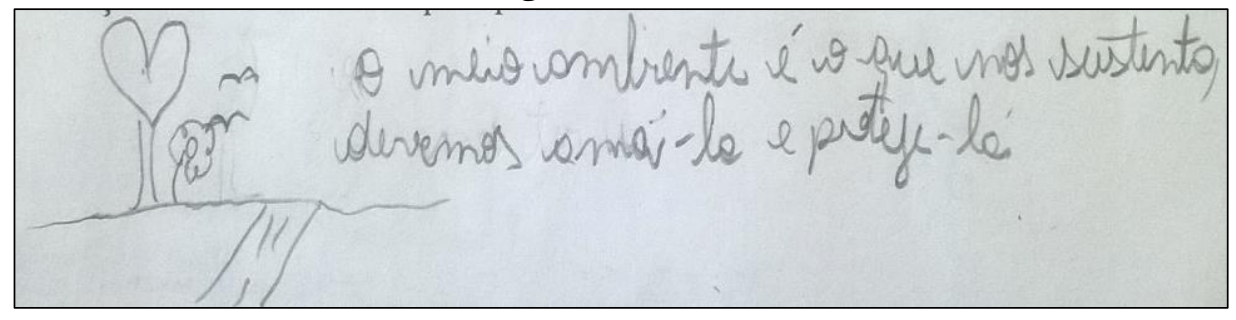

Fonte: Dados da pesquisa

Nessa frase, se nota o entendimento de MA com caráter recursista e antropocêntrico, ao passo que expõe que os recursos são imprescindíveis para a existência humana, devendo, por isso, ser cuidado e protegido. Ademais, essa frase contribui com o significado do desenho. A natureza, com seus recursos, é um lugar idealizado, necessitando ser zelado e protegido, justificando a representação do coração na imagem.

Com a análise da entrevista, notamos que A9 foi alterado de subcategoria e que A3 foi incluído nessa, a qual ficou constituída pelos alunos A2, A3 e A10. Durante a justificativa do desenho elaborado, A2 aponta:

\begin{abstract}
A2 - "Então, eu quis representar que o coração é o que nos sustenta, que nem, o coração não, o meio ambiente, na forma de representação de um coração, que o nosso coração a gente tem, então ela faz parte da natureza. Tudo o que tem na natureza faz parte de nós, é uma inter-relação. E com isso, a gente deve amar e proteger, como a gente cuida de nós, a gente não vai querer o mal pra nós, então a gente vai querer o bem também da natureza".
\end{abstract}

Nota-se que A2 faz uma analogia entre a árvore e o coração humano, expressando que ambos são importantes, necessários para a existência. Nesse sentido, pode-se fazer um paralelo com a árvore que libera oxigênio, bem como com os demais elementos e recursos presentes na natureza. Além disso, deixa-se claro que o MA sustenta a vida, por isso é essencial preservá-lo. Então, com o exposto, percebe-se uma visão recursista e antropocêntrica, visto que se evidencia uma preocupação com os recursos da natureza para utilização ou benefício humano, ou seja, MA como fonte de recursos para as pessoas, esquecendo-se dos demais organismos existentes.

Portanto, em uma percepção antropocêntrica, são consideradas apenas as relações entre os seres humanos, restando à natureza um valor instrumental, apenas de utilidade para as pessoas. Por isso, há a preocupação com os recursos, com sua finitude, mobilizando as pessoas na atuação da conservação ambiental. De acordo com Sauvé 


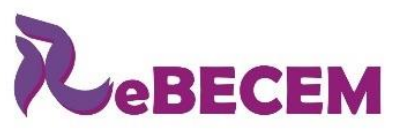

Revista Brasileira de Educação em

Ciências e Educação Matemática

DOI: https://doi.org/10.33238/ReBECEM.2020.v.4.n.2.24230

(2005, p. 317), considerar o MA como 'Recurso' implica atuar na conservação ambiental, uma vez que "[...] não existe vida sem os ciclos de recursos de matéria e energia".

Essas características de percepção de MA também estiveram presentes no trabalho de Maknamara (2009), evidenciando, nos relatos dos sujeitos pesquisados, a relevância da natureza e de seus recursos para a vida humana. Da mesma forma, na pesquisa de Correia (2014), com estudantes de licenciatura de um curso superior, foi destacada pelos sujeitos a compreensão do ser humano no centro do MA, como usufruidor, ao invés de uma visão ecocêntrica, segundo a qual o homem está inserido no MA como parte dele.

Conforme argumentado por Grün (2007), a presença desse entendimento sobre MA se justifica pela tradição ética ocidental, tradição segundo a qual a natureza é considerada como um domínio do homem, podendo este utilizá-la como bem entender. Essa visão ocidental pressupõe os homens não fazerem mal a outros homens, porém não discutindo a relação do homem com a natureza, atribuindo valor apenas instrumental às entidades não humanas.

Esse apontamento corrobora o entendimento apresentado por Reigota (2009) ao discutir que o ser humano não se considera parte da natureza, mas como observador ou explorador dela, contribuindo para a realização de ações exercidas sem a reflexão ou crítica sobre as consequências geradas, reforçando a visão antropocêntrica, na qual o ser humano é o ser mais evoluído, restando aos demais seres vivos a finalidade de servi-lo.

As implicações para a educação com a presença de educadores com essa percepção são inúmeras, dentre elas um ensino enfocado em atividades sem reflexão sobre a complexidade ambiental e de sua responsabilidade no planeta. De acordo com Corrêa e Barbosa (2018, p.133):

\begin{abstract}
Enquanto a EA nas escolas estiver pautada em práticas nas quais se reduz a atividades pontuais e meramente informativas voltadas simplesmente para a separação do lixo e para a economia de energia e água, desprovidas da reflexão e do questionamento sobre o nosso papel no processo como um todo, certamente a consciência ambiental (ativa e crítica) estará longe de ser promovida no ideário de uma sociedade ecológica, sustentável, ética e politicamente engajada.
\end{abstract}

Nesse sentido, os profissionais da educação devem ter acesso a informações ecologicamente corretas e ter atitudes ambientalmente adequadas, uma vez que a EA é um processo permanente de aprendizagem (CHAVES; GAIA, 2014; JACOBI, 2003).

O entendimento de MA como Lugar em que se vive também esteve presente no conjunto de estudantes investigado. Nessa subcategoria foram englobadas as percepções que enfatizaram ou retrataram o ambiente do cotidiano, a escola, as casas, as moradias, o 


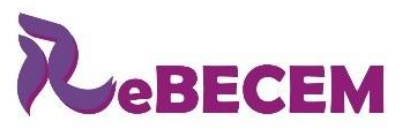

\section{Revista Brasileira de Educação em \\ Ciências e Educação Matemática}

DOI: https://doi.org/10.33238/ReBECEM.2020.v.4.n.2.24230

lugar de trabalho, o bairro, entre outros locais, situados em zona rural ou em espaço urbano (SAUVÉ, 2005; KRZYSCZAK, 2016).

A partir da análise do questionário e da entrevista, essa subcategoria ficou constituída apenas pelo estudante A3, o qual elaborou o seguinte desenho:

Figura 4: A3

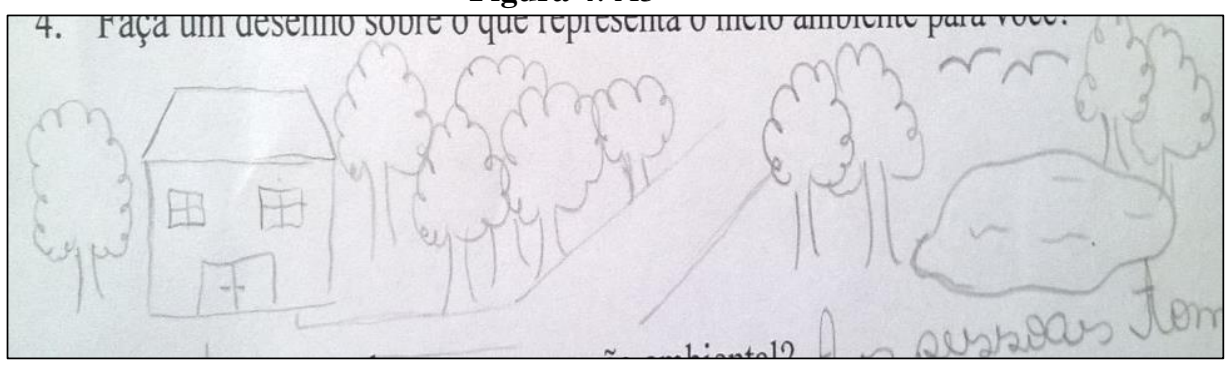

Fonte: Dados da pesquisa

Realizando o processo de dissecação, conforme Pen (2002), observa-se no desenho de A3, a presença de árvores, casa, açude, pássaros e rua. Possivelmente, a disposição e organização dos elementos no desenho nos remetem a uma moradia na zona rural, pois possui apenas uma casa, que é rodeada por árvores e um açude, o que pode ser entendido como um local de lazer. Por isso, acredita-se que a compreensão de MA exposta no desenho de A3 se inclina para o Lugar em que vive, sua moradia, conforme trechos: A3 - "É, dá uma representação da minha casa quase, bem parecido".

A3 - "Porque eu pensei mesmo na minha casa, e é o que a gente mais precisa, né, por exemplo, as árvores que hoje em dia tem muito desmatamento, então a gente precisa o reflorestamento, né! Temos que preservar essas matas que existem, então...".

Nos trechos, A3 expõe que fez referência à sua casa, confirmando a percepção de MA como Lugar em que se vive; porém, A3 também demonstra preocupação com os recursos ambientais, por evidenciar no desenho e em sua fala as árvores e sua relevância. Esse dado forneceu subsídios para alocá-lo também na subcategoria Recurso.

Essa percepção como Recurso, com traços de um viés conservador em relação ao MA, está atrelada com o desenvolvimento de ações individuais de preservação e reciclagem, não instigando os cidadãos a questionarem o sistema econômico que desmata em grande escala em prol dos interesses de poucos e/ou utilizando como justificativa a busca pelo desenvolvimento.

Para a educação, de acordo com Saheb (2015), o viés conservador não consegue responder as demandas atuais da EA, pois a contemporaneidade impõe novos desafios à cidadania. Nesse sentido, é preciso que a educação transpasse a reprodução de 


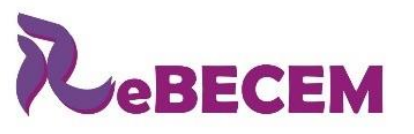

Revista Brasileira de Educação em

Ciências e Educação Matemática

DOI: https://doi.org/10.33238/ReBECEM.2020.v.4.n.2.24230

conhecimento e a prática pedagógica acrítica, para que possa contribuir no preparo dos estudantes para participarem e vivenciarem as potencialidades do conhecimento.

Além do exposto, a referência ao reflorestamento e à preservação das matas remete ao desmatamento, problema ambiental tão presente na sociedade. Essa informação demostra que A3 percebe a existência de problemas ou impactos ambientais na sociedade, e que para tanto se faz necessário realizar diversas atividades para diminuir ou mitigar as consequências ambientais, sociais e culturais. Por isso, A3 também constitui a subcategoria de MA como Problema.

De acordo com Sauvé (2005), o MA compreendido como Problema possui como características as propostas de ações de prevenção e de resolução de problemas ambientais, conforme exposto por A3 na entrevista. Segundo Krzysczak (2016, p. 6), essa percepção é gerada pela "[...] crescente urbanização, industrialização acelerada, monocultura, modos de vida e hábitos de consumo da população vinculados ao tipo de desenvolvimento vigente". Na contemporaneidade, os padrões de vida incitaram a presença dessa percepção de MA na sociedade, levando a população a perceber os danos ambientais existentes; entretanto, poucos são os que pensam reflexivamente sobre a gênese desses problemas e dos fatores a serem ponderados para a sua resolução ou mitigação.

No ambiente escolar, é preciso que os educadores abordem problemas ambientais locais e globais para instigar a reflexão sobre a EA, e possibilitar que os alunos apresentem possíveis resoluções para a questão ambiental proposta, dessa forma os sujeitos terão conhecimento sobre o MA para participar das discussões, argumentando nas decisões. De acordo com Diniz e Tomazello (2005, p.84-85) “O conhecimento sobre meio ambiente deve ser utilizado pra compreender a sua realidade, procurar soluções para problemas próximos e participar das soluções e decisões de sua comunidade", bem como das questões mais globais. Diante disso, concordando com o apontado por Araújo e Pedrosa (2014), os cursos de formação docentes devem buscar que seus discentes realizem:

[...] leituras coerentes com a complexidade da realidade ambiental. [...] Reconheçam as múltiplas inter-relações das questões ambientais, econômicas e sociais, locais e globais, numa visão sistêmica do ambiente. [...] Desenvolvam competências para analisar os conflitos socioambientais, debater propostas de resolução e tomar decisões individuais e coletivas (ARAÚJO; PEDROSA, 2014, p. 81).

Nessa perspectiva, a análise da entrevista permitiu que A3 fosse incluído na subcategoria de MA como Lugar em que se vive, Recurso, e como Problema. Esse dado, 


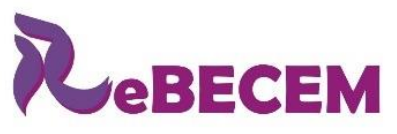

Revista Brasileira de Educação em

Ciências e Educação Matemática

DOI: https://doi.org/10.33238/ReBECEM.2020.v.4.n.2.24230

juntamente com a alteração de A9 para uma subcategoria diferente do questionário, possibilita compreender a relevância da entrevista com os alunos, os produtores dos desenhos, permitindo alocá-los em outra subcategoria ou em mais de uma, de acordo com a significação apresentada pelos mesmos sobre suas produções. Consideramos que as análises realizadas pelos autores das ilustrações denotam indicativos de reflexão, reelaboração e ampliação de seus conceitos de EA.

\section{Considerações Finais}

A análise das informações reunidas sobre as percepções de MA dos alunos do último ano da formação docente permitiu inferir que, dos 15 estudantes participantes, seis entendem que o MA engloba as diferentes espécies animais e vegetais, bem como os aspectos sociais, naturais, culturais e econômicos envolvidos, abrangendo uma percepção de Meio Ambiente como Biosfera. Possivelmente, esses futuros professores, ao lecionarem sobre educação ambiental e sobre o MA, apresentarão conteúdos mais significativos e completos, buscando abranger os diferentes aspectos e elementos envolvidos. Além disso, espera-se que esses futuros professores consigam abordar o conhecimento com criticidade, ampliando o espectro de questionamentos e implicações sociais e ambientais das ações realizadas no MA.

Por outro lado, também houve seis alunos que entendem o MA apenas como sinônimo de Natureza. Essa percepção, se não modificada, pode ser estendida a seus futuros alunos, influenciando na construção da percepção destes. Seus aprendizes podem ficar com uma percepção restrita sobre a compreensão de MA, fazendo relações apenas com os ambientes verdes, plantas e animais. Porém, o MA não pode ser reduzido ao ambiente físico e biológico, pois ele também abrange questões econômicas, culturais e sociais (BOTON et al., 2010).

Considerando a presença significativa dessa subcategoria neste trabalho e em outros, como de Garrido e Meirelles (2014) e Wollmann, Soares e Ilha (2015), e das demais subcategorias percebidas nos sujeitos pesquisados, somado com o fato da inexistência nas falas dos estudantes sobre as relações do MA com os sistemas econômicos e políticos, leva-nos a perceber uma carência nos cursos de formação docente sobre questionamentos e posicionamentos críticos sobre as questões ambientais, necessitando o aprofundando das discussões acerca das relações dos processos sociais e 


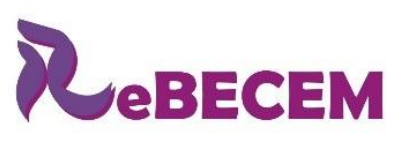

Revista Brasileira de Educação em

Ciências e Educação Matemática

DOI: https://doi.org/10.33238/ReBECEM.2020.v.4.n.2.24230

econômicos inerentes nesse processo. Uma vez que o ser humano age e sofre influências do meio, interpretando-o de acordo com a sua construção pessoal.

Os estudantes investigados devem buscar ampliar seus conhecimentos sobre a temática ambiental para poderem modificar seus posicionamentos e percepções. Dessa forma poderão contribuir positivamente na formação de seus futuros alunos, permitindo reflexões e participações nas discussões socioambientais de forma responsiva e consciente das consequências.

Posto isto, instigam-se novos posicionamentos sociais e políticos frente às problemáticas ambientais tão presentes na contemporaneidade pela globalização, por meio de notícias de catástrofes ecológicas com grande repercussão na mídia, afetando os ecossistemas e ameaçando a sobrevivência das espécies animais e vegetais, bem como a necessidade de crítica ao consumo e descarte de produtos de forma demasiada, sem realizar uma análise sobre a origem, a produção e o descarte destes.

Nesse panorama, entendemos que os sujeitos, e em específico os professores, devem estar em constante processo de formação, para ampliar sua compreensão de mundo e MA, para possibilitar discursos fundamentados e coerentes com a realidade, evitando entendimentos ingênuos e acríticos ao reduzir o MA à natureza, desconsiderando os aspectos sociais, políticos, econômicos, entre outros envolvidos, contribuindo para sua própria formação cidadã e de seus futuros alunos.

\section{Referências}

ARAÚJO, M. F. F.; PEDROSA, M. A. Desenvolvimento sustentável e concepções de professores de biologia em formação inicial. Revista Ensaio, Belo Horizonte, v.16, n. 02, p. 7183, maio/ago. 2014.

BARDIN, L. Análise de conteúdo. Tradução de Luís Antero Reto e Augusto Pinheiro. São Paulo: Martins Fontes, 1977.

BOTON, J. M.; COSTA, R. G. A.; KURZMANN, S. M.; TERRAZZAN, E. A. O meio ambiente como conformação curricular na formação docente. Revista Ensaio, Belo Horizonte, v.12, n.03, p.41-50, set./dez. 2010.

BRASIL, Decreto-Lei $n^{\circ}$ 6.938, de 31 de agosto de 1981. Dispõe sobre a Política Nacional do Meio Ambiente, seus fins e mecanismos de formulação e aplicação, e dá outras providências. Diário Oficial da República Federativa do Brasil, Brasília, DF, 31 de agosto de 1981. Disponível em: < http://www.planalto.gov.br/ccivil_03/LEIS/L6938.htm>. Acessado em: 14 abr. 2016.

BRÜGGER, P. Educação ou adestramento ambiental. 3. ed. Florianópolis: Letras Contemporâneas, 2004.

ReBECEM, Cascavel, (PR), v.4, n.2, p. 202-224, ago. 2020 


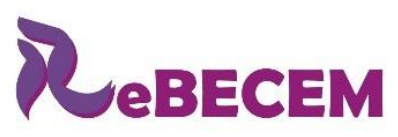

\section{Revista Brasileira de Educação em \\ Ciências e Educação Matemática \\ ISSN 2594-9179}

DOI: https://doi.org/10.33238/ReBECEM.2020.v.4.n.2.24230

CHAVES, R. A.; GAIA, M. C. M. O papel da escola na construção da Educação Ambiental: ações e reflexões. Revista da SBEnBIO, v. 7, p. 6356-6368, 2014.

CORREIA, M. M. Concepções de futuras professoras do ensino básico acerca do ambiente, da educação ambiental e das estratégias didáticas em educação ambiental. Revista Ensaio, Belo Horizonte, v. 16, n. 1, p. 15-29, jan./abr. 2014.

CUNHA, M. B. A percepção de ciência e tecnologia dos estudantes de ensino médio e a divulgação científica. 2009. Tese (Doutorado em Educação) - Faculdade de Educação da Universidade de São Paulo, São Paulo, 2009.

DIAS, G. F. Educação Ambiental: princípios e práticas. 9. ed. São Paulo: Gaia, 2004.

DIAS, K. F. Abordagem ambiental nos livros didáticos de química aprovados pelo PNLEM 12007: princípios da carta de Belgrado. 2012. Dissertação (Mestrado em Ciências Exatas e da Terra) - Universidade Federal de Goiás, Goiânia, 2012.

DINIZ, E. M.; TOMMASIELLO, M. G. C. A pedagogia da complexidade e o ensino de conteúdos atitudinais na Educação Ambiental. Revista Eletrônica Mestrado Educação Ambiental, Rio Grande, v. 15, n. 1, p. 80-93, 2005.

FLICK, U. Introdução à pesquisa qualitativa. 3. ed. Porto Alegre, RS: Artmed, 2009.

GARRIDO, L. S.; MEIRELLES, R. M. S. Percepção sobre meio ambiente por alunos das séries iniciais do ensino fundamental: considerações à luz de Marx e de Paulo Freire. Ciência \& Educação, Bauru, v. 20, n. 3, p. 671-685, jul./set. 2014.

GRÜN, M. A pesquisa em ética na educação ambiental. Pesquisa em Educação Ambiental, São Paulo, v. 2, n. 1, p. 185-206, jan./jun. 2007.

JACOBI, P. Educação ambiental, cidadania e sustentabilidade. Cadernos de Pesquisa, São Luís, n. 118, p. 189-206, 2003.

KRZYSCZAK, F. R. As diferentes concepções de meio ambiente e suas visões. Revista de Educação do Ideau, Alto Uruguai. v. 11, n. 23, p. 1-17, jan./jun. 2016.

LURIA, A. R. Desenvolvimento cognitivo: seus fundamentos culturais e sociais. Tradução de GURGUEIRA, F. L. 4. ed. São Paulo: Ícone, 1990.

LURIA, A. R. Vigotski. In: VIGOTSKII, L. S.; LURIA, A. R.; LEONTIEV, A. N. (org.). Linguagem, desenvolvimento e aprendizagem. Tradução de VILLALOBOS, M. P. São Paulo: Ícone, 2001. p. 21-38.

MAKNAMARA, M. Educação ambiental e ensino de ciências em escolas públicas alagoanas. Contrapontos, Itajaí, v. 9, n. 1, p. 55-64, jan./abr. 2009.

MARCONI, M. A.; LAKATOS, E. M. Metodologia cientifica. 5. ed. São Paulo: Atlas, 2011.

MARIANI JÚNIOR, R. O estudo de ecologia no ensino médio: uma proposta metodológica alternativa. 2008. Dissertação (Mestrado em Ensino de Ciências e Matemática) - Pontifícia Universidade Católica de Minas Gerais, Belo Horizonte, 2008.

MINAYO, M. C. S. Análise e interpretação de dados de pesquisa qualitativa. 29. ed. Petrópolis, RJ: Vozes, 2010. 
DOI: https://doi.org/10.33238/ReBECEM.2020.v.4.n.2.24230

MORAES, R. Análise de conteúdo. Revista Educação, Porto Alegre, v. 22, n. 37, p. 7-32, 1999.

OENNING, V.; CARNIATTO, I. Implicações das Representações Sociais de Meio Ambiente na relação Homem-Natureza para a Educação Ambiental: um estudo a partir das definições de alunos moradores da zona rural do Paraná. Educação Ambiental em Ação, n.38, dez. 2011. Disponível em: <http://www.revistaea.org/artigo.php?idartigo=1166>. Acesso em: 16 mar. 2017.

OLIVEIRA, A. R. A.; AMORIM, R. M.; PIZZI, L. C. V. Disciplina Profissão Docente em um curso de Pedagogia: trajetórias, experiências e inovações na formação docente. Revista Eletrônica de Educação, São Carlos, v. 12, n. 1, p. 263-278, jan./abr. 2018.

PEN, G. Análise semiótica de imagens paradas. In: BAUER, M. W.; GASKELL, G. (ed.). Pesquisa qualitativa com texto, imagem e som. Petrópolis, RJ: Vozes, 2002. p. 319-342.

RAMOS, E. C. Educação ambiental: origem e perspectivas. Educar, Curitiba, v.17, n.18, p. 201-218, 2001.

REIGOTA, M. Meio ambiente e representação social. 3 ed. São Paulo: Cortez, 1998.

REIGOTA, M. O que é educação ambiental. 2 ed. São Paulo: Brasiliense, 2009.

SAHEB, D. Os sete saberes necessários à educação do futuro e a educação ambiental na formação de professores: uma discussão à luz das diretrizes curriculares nacionais para a educação ambiental (2012). Pesquisa em Educação Ambiental, Rio Claro, v. 10, n. 1, p. 57 69, 2015.

SANTOS, E. L.; MAROTI, P. S. Educação Ambiental Naturalista e Conservacionista: Validação do RPG 'Jogo do Parque' (Parque Nacional Serra De Itabaiana). In: ENCONTRO SERGIPANO DE EDUCAÇÃO AMBIENTAL, 4., 2013, São Cristóvão. Anais... São Cristóvão: UFS, 2013. p.12-31.

SAUVÉ, L. Educação ambiental: possibilidades e limitações. Educação e Pesquisa, São Paulo, v. 31, n. 2, p. 317-322, maio/ago. 2005.

SAWAIA, B. B. Espinosa: o precursor da ética e da educação ambiental com base nas paixões humanas. In: CARVALHO, I. C. de M.; GRÜN, M.; TRAJBER, R. (org.). Pensar o ambiente: bases filosóficas para a educação ambiental. Brasília: MEC/UNESCO, 2006, p.79-92.

SILVA, C. O. Direito do Ambiente. In: ZACARIAS, R.; PINTO, V. P. dos S. (org.). Educação Ambiental em Perspectiva. 1. ed. Juiz de Fora: FEME, 2002.

SILVA, J. A. Direito ambiental constitucional. 3. ed. São Paulo: Malheiros Editores. 2000.

SILVA, S. N. Concepções e Representações Sociais de Meio Ambiente: uma revisão crítica da literatura. In: ENCONTRO NACIONAL DE PESQUISA EM EDUCAÇÃO EM CIÊNCIAS, 7., 2009. Florianópolis. Anais... Florianópolis: ABRAPEC, 2009. p. 1-12.

TOZONI-REIS, M. F. C. Educação Ambiental: natureza, razão e história. Campinas: Autores Associados, 2004.

VIGOTSKI, L. S. A formação social da mente: o desenvolvimento dos processos psicológicos superiores. 6. ed. COLE, M.; SCRIBNER, S. (org.). CIPOLLA NETO, J. et al. (Trad.). São Paulo: Martins Fontes, 1998. 
DOI: https://doi.org/10.33238/ReBECEM.2020.v.4.n.2.24230

WOLLMANN, E. M.; SOARES, F. A. A.; ILHA, P. V. As percepções de educação ambiental e meio ambiente de professoras das séries finais e a influência destas em suas práticas docentes. Revista Brasileira de Pesquisa em Educação em Ciências, Belo Horizonte, v. 15, n. 2, p. 387-405, maio/ago. 2015.

Recebido em: 10 de março de 2020

Aceito em: 20 de julho de 2020 